\title{
Research on the Influence of Unclosed Residential Community on the Surrounding Road Network
}

\author{
Yujun Deng, Xiaoning Zhu \\ School of Traffic and Transportation, Beijing Jiaotong University \\ Beijing, China \\ 17120787@bjtu.edu.cn, xnzhu@bjtu.edu.cn
}

\begin{abstract}
In this study, in order to analyze the influence of unclosed residential community on the surrounding road network, a method of road network capacity evaluation was proposed, and the model of traffic flow distribution was constructed to quantitatively describe the vehicle route selection in the road network. Then, based on the mathematical model, the quantitative calculations were performed on the two cases of closed residential community and unclosed residential community. According to the calculation results, the traffic capacity of the surrounding road network of the two types of residential communities was compared and analyzed, and we put forward some reasonable suggestions.
\end{abstract}

Keywords-unclosed residential community; traffic flow distribution; urban traffic

\section{INTRODUCTION}

With the rapid development of economy and society in China, the urban population has grown rapidly and the traffic congestion has become increasingly serious. In view of the road networks with low density in most cities in China, the government proposes that closed residential communities should be gradually opened. Many scholars began to study whether the opening of a closed communities is conducive to alleviating traffic congestion and how to open a closed community. Landman[1] elaborated that closed communities cut off the urban road network, making the accessibility of roads lower, and proposed a strategy for sustainable development between communities and cities. Handy[2] proposed to improve the accessibility of road networks by linking roads within the community to solve the problem of poor urban traffic. Moore[3] proposed that the integration of community and transportation land can improve the efficiency of urban transportation. Based on the experience of urban development in the Asia-Pacific region, $\mathrm{Li}[4]$ proposed to create a "semi-open" residential community to solve the current urban traffic congestion problem. Yan[5] analyzed the partial road network of Daqing City and pointed out that the opening of the internal roads in the closed community could improve the local traffic conditions. This study will analyze the impact of unclosed residential community on the surrounding road network through quantitative analysis.

The above content is the introduction of the unclosed residential community. The rest of this paper is organized as follows: The method of network capacity evaluation is described in Section 2. And the model of traffic flow

Major Research Plan of the National Natural Science Foundation of China [grant number 71390332]; Fundamental Research Funds for the Central Universities [grant number 2017YJS100]; Major Project of Civil Aviation Science and Technology Project [project number 201501]. distribution is given in Section 3. Computational experiments on the closed residential community and the unclosed one are discussed in Section 4 and finally Section 5 presents the conclusion.

\section{THE METHOD OF ROAD NETWORK CAPACITY EVALUATION}

\section{A. Establish the index system}

By literature review, we summarized that the main factors affecting the road network capacity include road congestion, average vehicle speed, and road delay time. Based on the Analytic Hierarchy Process (AHP), the road network capacity is used as the target layer, and the road congestion $\left(\mathrm{T}_{1}\right)$, average vehicle speed $\left(T_{2}\right)$, and road delay time $\left(T_{3}\right)$ are used as evaluation indicators. The index system of road network capacity is shown in Fig 1.

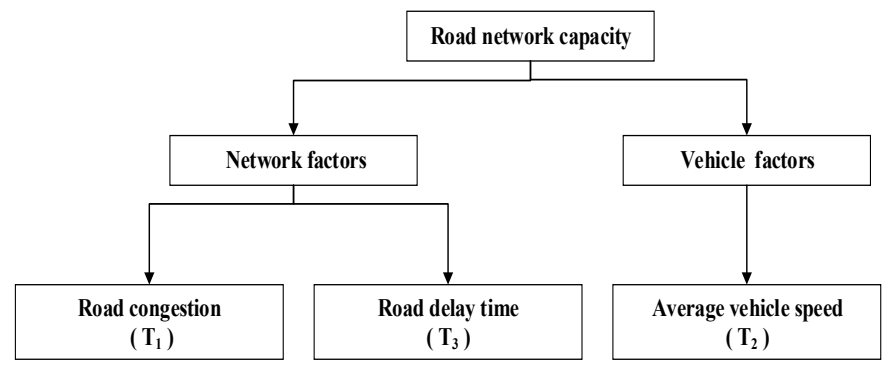

Fig. 1. The index system of road network capacity.

According to the actual situation of urban traffic in Beijing, we give the values of each index. The evaluation scores corresponding to the values of each index specified in this article are shown in Table I below. 
TABLE I. THE SCORES CORRESPONDING TO THE VALUES OF EACH INDEX

\begin{tabular}{|c|c|c|c|c|c|}
\hline \multirow{2}{*}{$\begin{array}{c}\text { Road } \\
\text { congestion }\end{array}$} & $\begin{array}{l}\text { Values } \\
\text { of } T_{1}\end{array}$ & $0-0.2$ & $0.2-0.4$ & $0.4-0.6$ & $0.6-1$ \\
\hline & Scores & $100-90$ & $90-80$ & $80-70$ & $70-60$ \\
\hline \multirow{3}{*}{$\begin{array}{l}\text { Average } \\
\text { vehicle } \\
\text { speed }\end{array}$} & Values & $60-40$ & $40-30$ & $30-20$ & $<20$ \\
\hline & of $\mathrm{T}_{2}$ & $\mathrm{~km} / \mathrm{h}$ & $\mathrm{km} / \mathrm{h}$ & $\mathrm{km} / \mathrm{h}$ & $\mathrm{km} / \mathrm{h}$ \\
\hline & Scores & $100-90$ & $90-80$ & $80-70$ & $<70$ \\
\hline \multirow{2}{*}{$\begin{array}{l}\text { Road delay } \\
\text { time }\end{array}$} & $\begin{array}{l}\text { Values } \\
\text { of } \mathrm{T}_{3}\end{array}$ & $0-20 \mathrm{~s}$ & $20-30 \mathrm{~s}$ & $30-40 \mathrm{~s}$ & $>40 \mathrm{~s}$ \\
\hline & Scores & $100-90$ & $90-80$ & $80-70$ & $<70$ \\
\hline
\end{tabular}

B. Calculate the weights of each index

According to the actual situation of urban traffic in Beijing, we first established a pairwise comparison matrix A as follows.

$$
A=\left(\begin{array}{ccc}
1 & \frac{1}{5} & \frac{1}{3} \\
5 & 1 & 3 \\
3 & \frac{1}{3} & 1
\end{array}\right)
$$

This paper uses MATLAB software to complete the AHP process. After calculation, the normalized weights of each evaluation index meet the consistency inspection requirements. The index weights are shown in Table II below.

TABLE II. THE WEIGHTS OF EACH INDEX

\begin{tabular}{|c|c|c|c|}
\hline Indexes & $\mathrm{T}_{1}$ & $\mathrm{~T}_{2}$ & $\mathrm{~T}_{3}$ \\
\hline Weights & 0.1047 & 0.6370 & 0.2583 \\
\hline
\end{tabular}

The comprehensive evaluation score (CES) can be calculated as:

$$
C E S=0.1047 \times T_{1}+0.6370 \times T_{2}+0.2583 \times T_{3}
$$

\section{THE TRAFFIC FLOW DISTRIBUTION MODEL}

Based on the principle of Wardrop Equilibrium, this section proposes a traffic flow distribution model.

Wardrop's first principle of route choice (User equilibrium) describes the spreading of trips over alternate routes because of congested conditions. It states that the travel times in all routes actually used are equal and less than those that would be experienced by a single vehicle on any unused route. This paper is to study the influence of the open state of the residential community on the road network capacity, in essence, that is, the impact of the closed residential community and the unclosed one on the driver's route selection behaviors. Therefore, this paper builds the model of road network traffic flow distribution based on User Equilibrium.
Ts

$q_{r s}$

$K_{i j}$

\section{A. Parameters and variables}

The parameters and variables of the distribution model are introduced in Table III.

TABLE III. PARAMETERS AND VARIABLES

\begin{tabular}{cc}
$\begin{array}{c}\text { Parameters } \\
\text { and } \\
\text { Variables }\end{array}$ & Declaration \\
\hline$N$ & Set of nodes in the network. \\
$L$ & Set of lines in the network. \\
$R$ & Set of origin nodes. \\
$S$ & Set of destination nodes. \\
$W_{r s}$ & $\begin{array}{c}\text { Set of all routes from origin node } \\
\text { r to destination node s. }\end{array}$ \\
$q_{r s}$ & $\begin{array}{r}\text { OD traffic volume from origin } \\
\text { node } \mathrm{r} \text { to destination node s. } \\
K_{i j}\end{array}$ \\
& $\begin{array}{r}\text { Number of all routes from node i } \\
\text { to node j. }\end{array}$
\end{tabular}

Traffic volume of the k-th route

$f_{k}^{r s}$ from origin node $r$ to destination node $\mathrm{s}$.

Traffic volume of line $(i, j)$.

Traffic impedance of line $(i, j)$, i.e., travel time.

Zero-current impedance, i.e., the time required for the vehicle to travel freely when the road is empty.

The actual capacity of line (i,j), i.e., the number of vehicles actually passing through line $(i, j)$ during the unit time.

$\alpha, \beta$

Retardation coefficient, U.S. Highway Administration sets $\alpha=0.15, \beta=4$.

A binary variable that equals 1 if line $(i, j)$ belongs to the kth route of the OD pair $\langle\mathrm{r}, \mathrm{s}\rangle$, and 0 otherwise. 


\section{B. The mathematical model}

The nonlinear programming model is formulated as follows.

$$
\begin{aligned}
\min Z(x) & =\sum_{i \in N} \sum_{j \in N} \int_{0}^{x_{i j}} t_{i j}(\omega) d \omega \\
& =\sum_{i \in N} \sum_{j \in N} \int_{0}^{x_{i j}} t_{0}\left[1+\alpha\left(\frac{\omega}{c_{i j}}\right)^{\beta}\right] d \omega
\end{aligned}
$$

Subject to

$$
\begin{gathered}
x_{i j}=\sum_{r \in R} \sum_{s \in S} \sum_{k \in K_{i j}} f_{k}^{r s} \delta_{\mathrm{ij}, k}^{r s}, \quad \forall(i, j) \in L \\
\sum_{k \in K_{r s}} f_{k}^{r s}=q_{r s}, \quad \forall\langle r, s\rangle \in W_{r s} \\
f_{k}^{r s} \geq 0, \quad \forall\langle r, s\rangle \in W_{r s}, \quad \forall k \in K_{r s}
\end{gathered}
$$

The objective function is to minimize the total travel time of all traffic volumes in the overall road network. Constraint (3) ensures that the total volume on the line $(i, j)$ is equal to the sum of the volume flowing through the line $(i, j)$ in the network. Constraint (4) ensures that the total traffic volumes from origin node $r$ to destination node $s$, is equal to the sum of the traffic volume of the different routes from origin node $r$ to destination node s. Constraint (5) ensures that $f_{k}^{r s}$ is non-negative.

The model proposed in this research is a nonlinear programming model. The software MTLAB can solve the linear and nonlinear optimization problems. Therefore, we chose MTLAB to solve this problem.

\section{CASE STUDY}

\section{A. The case of closed residential community}

We assume that the shape of the closed residential community is a rectangle with a length of $500 \mathrm{~m}$ and a width of $500 \mathrm{~m}$. The community is surrounded by four trunk roads. Each trunk road is a two-way six-lane road. Its one-way capacity is $3000 \mathrm{pcu} / \mathrm{h}$ and the design speed is $60 \mathrm{~km} / \mathrm{h}$. The road network of closed residential community is shown in Fig 2. Since there is an origin point and a destination point for each traffic volume, it may be assumed that the OD points of the traffic volume in the road network are both point 1 and point 3 . The traffic from point 1 to point 3 is 2000 , and the traffic from point 3 to point 1 is also 2000 . In addition, we assume that the standard car length is $5 \mathrm{~m}$, the minimum safety distance is $5 \mathrm{~m}$, and the vehicle speed $(v)$ and congestion parameter $(\rho)$ satisfy the equation $v=v_{f}(1-\rho)$, where $v_{f}$ is the design speed.

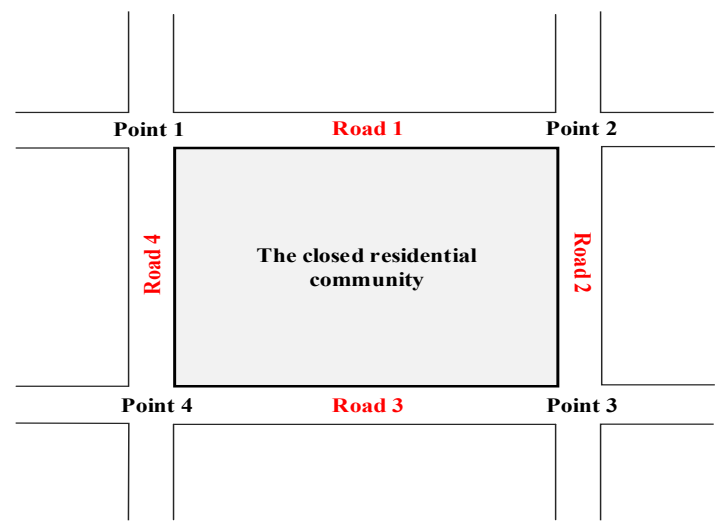

Fig. 2. The road network of closed residential community.

The above data is brought into the traffic flow distribution model. Then, the model is solved by MATLAB, and the traffic flows on the four roads are as follows.

$$
x_{1}=x_{2}=x_{3}=x_{4}=2000
$$

After getting traffic flow data for each road, we can calculate the road congestion degree, average vehicle speed and road delay time respectively, and then obtain corresponding evaluation scores based on the analytic hierarchy process. The specific results are shown in Table IV.

TABLE IV. EVALUATION RESULTS OF INDEXES OF ROAD NETWORK CAPACITY FOR CLOSED RESIDENTIAL COMMUNITY

\begin{tabular}{|c|c|c|c|}
\hline Indexes & $\mathrm{T}_{1}$ & $\mathrm{~T}_{2}$ & $\mathrm{~T}_{3}$ \\
\hline Values & 0.34 & $39.6 \mathrm{~km} / \mathrm{h}$ & $30.9 \mathrm{~s}$ \\
\hline Weights & 0.1047 & 0.6370 & 0.2583 \\
\hline Scores & 82 & 89 & 80 \\
\hline
\end{tabular}

According to the data in the above table, the comprehensive evaluation score (CES) can be calculated by equation (1), and the result is 85.94 .

\section{B. The case of unclosed residential community}

There is only one difference here between the closed residential community and the unclosed one. The difference is that a two-way road is opened in the residential community, its capacity is $600 \mathrm{pcu} / \mathrm{h}$, and the design speed is $60 \mathrm{~km} / \mathrm{h}$. The other conditions of the unclosed community are the same as those of the closed community described above. The road network of unclosed residential community is shown in Fig 3. 


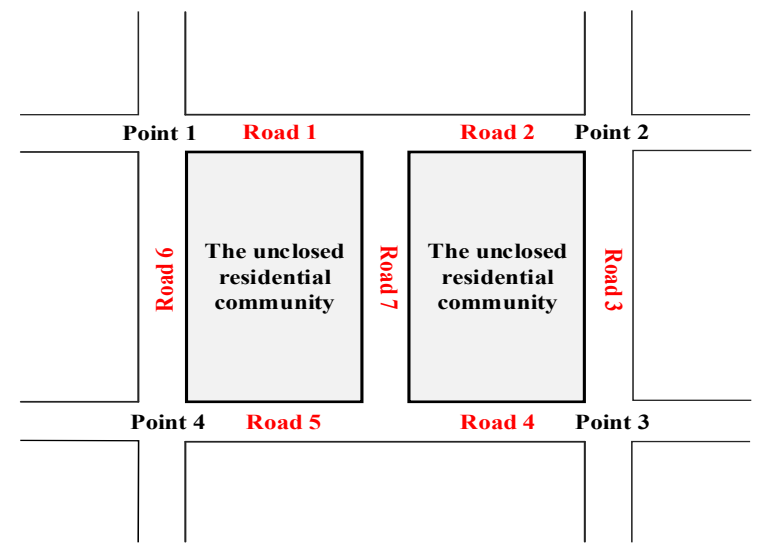

Fig. 3. The road network of unclosed residential community.

The above data is brought into the traffic flow distribution model. Then, the model is solved by MATLAB, and the traffic flows on the four roads are as follows.

$$
\begin{gathered}
x_{1}=2038, x_{2}=1962, x_{3}=1962, x_{4}=2038, \\
x_{5}=1962, x_{6}=1962, x_{7}=76 .
\end{gathered}
$$

Similar to the previous section, after the calculation, the evaluation results of indexes for unclosed residential community are shown in Table $\mathrm{V}$.

TABLE V. EVALUATION RESULTS OF INDEXES OF ROAD NETWORK CAPACITY FOR UNCLOSED RESIDENTIAL COMMUNITY

\begin{tabular}{|c|c|c|c|}
\hline Indexes & $\mathrm{T}_{1}$ & $\mathrm{~T}_{2}$ & $\mathrm{~T}_{3}$ \\
\hline Values & 0.32 & $40.8 \mathrm{~km} / \mathrm{h}$ & $28.2 \mathrm{~s}$ \\
\hline Weights & 0.1047 & 0.6370 & 0.2583 \\
\hline Scores & 86 & 89 & 83 \\
\hline
\end{tabular}

According to the data in the above table, the comprehensive evaluation score (CES) can be calculated by equation (1), and the result is 88.41 .

\section{CONCLUSIONS}

In this study, we use the mathematical model and the evaluation method to solve this problem, based on the rectangular residential community. According to the calculation results, we can see that the overall evaluation score of the unclosed residential community is higher than that of the closed one, that is, the overall traffic capacity of the road network has improved after the opening of the community. Therefore, the conclusion is that opening a two-way road in a rectangular residential area can improve the overall capacity of the surrounding road network of the residential community.

\section{ACKNOWLEDGMENT}

This work was supported by the Major Research Plan of the National Natural Science Foundation of China [grant number 71390332]; the Fundamental Research Funds for the Central Universities [grant number 2017YJS100] and Major Project of Civil Aviation Science and Technology Project [project number 201501].

\section{REFERENCES}

[1] Landman K. Gated communities and urban sustainability: taking a closer look at the future [J]. 2000.

[2] Handy S, Paterson R G, Butler K S. Planning for street connectivity: Getting from here to there [J]. Apa Planning Advisory Service Reports, 2003(515):1-75

[3] Moore T, Thorsnes P, Appleyard B, et al. The Transportation/Land Use Connection [J]. Apa Planning Advisory Service Reports, 2007(546).

[4] Li.Discussion on the planning and design mode of semi-open residential community[D].Zhejiang University,2013

[5] Yan, Ding. Research on Road Network Evaluation Considering the Use of Roads in Closed Communities [J]. China Urban Transport Planning Society 2005 Essays, 2005. 